\title{
A Demographic and Clinical Panorama of a Sixteen- Year Cohort of Soft Tissue Sarcoma Patients in Brazil
}

\section{Luiza Ohasi Figueiredo ( $\square$ luiza.ohasi@uol.com.br)}

Faculty of Medical Sciences of Minas Gerais (FCMMG)

\section{Augusto Afonso Guerra Júnior}

Federal University of Minas Gerais

Francisco Assis Acurcio

Federal University of Minas Gerais

Alessandra Maciel Almeida

Federal University of Minas Gerais

\section{Mariângela Leal Cherchiglia}

Federal University of Minas Gerais

Alberto Julius Alves Wainstein

Faculty of Medical Sciences of Minas Gerais (FCMMG)

Luiz Claudio Santos Thuler

Brazilian National Cancer Institute (INCA)

\section{Angélica Nogueira-Rodrigues}

Faculty of Medical Sciences of Minas Gerais (FCMMG)

\section{Research Article}

Keywords: soft tissue sarcoma, survival, epidemiology.

Posted Date: August 19th, 2021

DOl: https://doi.org/10.21203/rs.3.rs-798586/v1

License: (c) (i) This work is licensed under a Creative Commons Attribution 4.0 International License. Read Full License

Version of Record: A version of this preprint was published at Scientific Reports on November 18th, 2021. See the published version at https://doi.org/10.1038/s41598-021-02032-5. 


\section{Abstract}

Introduction: Little is known about soft tissue sarcomas (STS) in Brazil, once the federal statistics regarding estimates on incidence and mortality of the most common cancers that affect the Brazilian population currently do not include STS. This study aims to perform a broad evaluation and description of the epidemiological profile, access to treatment and main clinical outcomes of the Brazilian STS patient.

Methods: A population-based cohort study of 66,825 patients who underwent procedures related to STS treatment registered in the Brazilian public health system (Sistema Único de Saúde, SUS) databases.

Results: Median age was 57 years, $30 \%$ of them older than 65 years and $50.7 \%$ of the cohort was female. The majority, 50,383 patients (75.4\%), was diagnosed between 2008 and 2015. Most prevalent anatomic sites were head and neck (13.6\%) and upper and lower limbs (12.6\%). The registry of sarcomas without a specific location comprehended $29.7 \%$ of the cohort. The majority of patients resided in the Northeast ( $40.2 \%$ of the patients). Surgery was the first treatment modality in $77.7 \%$ of the cases. The $1-, 5$ - and $10-$ year survival rate of the patients was, respectively, $82.3 \%(95 \% \mathrm{Cl}=82 \%-82,7 \%), 57.4 \%(95 \% \mathrm{Cl}=$ $56.9 \%-58 \%)$ and $42 \%(95 \% \mathrm{Cl}=41.2 \%-42.9 \%)$.

\section{Introduction}

Soft-tissue Sarcomas (STS) are a rare and heterogenous group of neoplasms, derived from a myriad of mesodermal (or mesenchymal) cells distributed within the entire body, performing connective roles among over 50 subtypes based on their cell origin and histologic and molecular characteristics, and accounting for less than $1 \%$ of all adult solid malignant tumors ${ }^{(1)}$.

The Brazilian National Cancer Institute (INCA) publishes biannually statistics regarding estimates on incidence and mortality of the most common cancers that affect the Brazilian population, STS not included $^{(2)}$. Few studies about STS have been published in Brazil so far, most of them covering single institutions experiences, none addressing the consolidated Brazilian scenario. The purpose of this study is to perform a broad evaluation and description of the epidemiological profile, access to treatment and main clinical outcomes of the STS patients treated at the Brazilian public health system (Sistema Único de Saúde, SUS).

\section{Methods}

We conducted a retrospective cohort study of patients who underwent hospital and outpatient clinical and surgical procedures related to STS treatment in SUS from 01/01/2000 to 12/31/2015. A National Database of Health centered on the individual was built through a deterministic-probabilistic record linkage of three administrative databases: The Outpatient Information System (SIA/SUS), the Hospital Information System (SIH/SUS), and the Mortality Information System (SIM) (Figure 5). The construction and validation of this database has been described and validated elsewhere $(13,14)$, and it has been used in previous research 
studies published. The time period of the cohort was determined based on the data available within the database ${ }^{(13-17) .}$.

The study included patients with STS according to the tenth revision of the international classification of diseases (ICD-10) (oncologic diagnostic identified as C48, C48.0, C48.1, C48.2, C48.8, C49, C49.0, C49.1, C49.2, C49.3, C49.4, C49.5, C49.6, C49.8. or C49.9), submitted to any type of surgery or systemic treatment (chemotherapy and/or radiotherapy) as first course therapy related to their disease from 2000 to 2016 . The first registry of surgery, systemic treatment (chemotherapy), or radiotherapy in association with a respective STS ICD-10 was considered T0 ("time zero"; baseline). The event used for survival analysis was death registered by the Mortality Information Systems (SIM) (mandatory for all Brazilian population) and right censoring was defined as not observing/having registered death until December 2016.

The following variables were analyzed: age at diagnosis, country's region, sex, diagnosis' year, tumor anatomic location (identified according to the tenth revision of the international classification of diseases ICD-10), tumor grade at diagnosis $(5,18)$, clinical stage at diagnosis (Stage I: tumor is small and low grade GX or G1;Stage II: tumor is small and G2 or G3; Stage III: Tumor is larger and G2 or G3; and Stage IV: cancer has spread to other parts of the body), (any G) $(5,18)$ ), first course-therapy (surgery, chemotherapy, radiotherapy) and time of death.

- Statistical Analysis

Descriptive statistical analysis of all variables in this study was performed: frequency distribution for categorical variables and central tendency for continuous variables.

The Kaplan-Meier method was used to estimate the cumulative probability of survival and different survival curves were compared using the log-rank test. The hazard-ratio (HR) for progression to the event was calculated by univariate analysis considering a $95 \%$ confidence interval.

The management of the data and statistical analysis was performed using 'R' Version 1.3.1056 (R Foundation for Statistical Computing) and MySQL,19 version 5.0(Oracle Corporation), considering a significance level of $5 \%$.

\section{Results}

Data from 66,852 STS patients registered in the Brazilian national databases (Mortality Information Systems - SIM, Outpatient Information System - SIA/SUS, and Hospital Information System - SIH/SUS from 2000 to 2015 were obtained. These databases include information from public health services from the 26 Brazilian states and the Federal District. This cohort includes patients who underwent at least one of the following three procedures for STS: surgery, chemotherapy or radiotherapy.

Median age was 57 years, $33 \%$ of them older than 65 years. $50.7 \%$ of the cohort $(33,940)$ was female. The majority, 50,383 patients (75.4\%), was diagnosed between 2008 and 2015 (Table1). Most prevalent anatomic sites were head and neck (13.6\%), followed by upper and lower limbs (12.6\%). The registry rate of 
sarcomas without a determined location or characterized as invasive without a specific location (with ICD 10 identification as C498 and C499) comprehended $29.7 \%$ of the cohort (Table 1 ).

Sub-registration of tumor grade and clinical staging was observed, being GX (undefined) and clinical stage undetermined the most common register for these variables, $91.3 \%$ and $79.5 \%$, respectively (Table 1 ).

The majority of patients resided in the Northeast region ( $40.2 \%$ of the patients) and Southeast (35\% of the patients), followed by the South, Midwest and North regions (16.1\%, 5.6\%, 3.1\%, respectively). Other epidemiologic characteristics are summarized in Table 1.

Table 1: Epidemiologic Aspects of the Sarcoma Patient in Brazil 


\begin{tabular}{|c|c|c|}
\hline & & Soft-tissue Sarcoma \\
\hline \multicolumn{2}{|l|}{ Total } & $66,852(100 \%)$ \\
\hline \multirow[b]{2}{*}{ Sex } & Female & $33,940(50.7 \%)$ \\
\hline & Male & $32,912(49.3 \%)$ \\
\hline \multirow[t]{6}{*}{ Race } & Asian & $558(0.8 \%)$ \\
\hline & White & $12143(18 \%)$ \\
\hline & Indigenous & $9(0.01 \%)$ \\
\hline & Non-Caucasian (Mixed) & $8046(12 \%)$ \\
\hline & Black & $941(1.5 \%)$ \\
\hline & Undetermined & $45155(67.6 \%)$ \\
\hline \multirow[t]{5}{*}{ Region } & Midwest & $3720(5.6 \%)$ \\
\hline & Northeast & $26885(40.2 \%)$ \\
\hline & North & $2092(3.1 \%)$ \\
\hline & Southeast & $23378(35 \%)$ \\
\hline & South & $10777(16.1 \%)$ \\
\hline \multirow[t]{6}{*}{ Age at diagnosis } & $18--25$ & $4034(6 \%)$ \\
\hline & $26-35$ & $6308(9.4 \%)$ \\
\hline & $36-45$ & $8619(13 \%)$ \\
\hline & $46-55$ & $12249(18.3 \%)$ \\
\hline & $56-65$ & $13591(20.3 \%)$ \\
\hline & $>65$ & $22051(33 \%)$ \\
\hline \multirow[t]{4}{*}{ Year of diagnosis } & $2000-2003$ & $9170(13.7 \%)$ \\
\hline & $2004-2007$ & $7299(11 \%)$ \\
\hline & $2008-2011$ & $22957(34.3 \%)$ \\
\hline & $2012-2015$ & $27426(41 \%)$ \\
\hline \multirow[t]{5}{*}{ Sarcoma anatomic location } & Abdomen and pelvis & $3267(5 \%)$ \\
\hline & Head and neck & $15926(23.8 \%)$ \\
\hline & Lower limbs & $8441(12.6 \%)$ \\
\hline & Upper limbs & $8442(12.6 \%)$ \\
\hline & Peritoneum and retroperitoneum & $6668(10 \%)$ \\
\hline
\end{tabular}




\begin{tabular}{|lll|} 
& Thorax and torso & $4230(6.3 \%)$ \\
& Invasive without specific location & $9173(13.7 \%)$ \\
& Undetermined & $10705(16 \%)$ \\
\hline Tumor grade at diagnosis & G1 & $3524(5.3 \%)$ \\
& G2 & $635(1 \%)$ \\
& G3 & $1629(2.4 \%)$ \\
& GX & $61064(91.3 \%)$ \\
\hline Clinical stage at diagnosis & Stage 1 & $999(1.5 \%)$ \\
& Stage 2 & $2917(4.3 \%)$ \\
& Stage 3 & $3637(5.4 \%)$ \\
& Stage 4 & $6247(9.3 \%)$ \\
& Undetermined & $53052(79.5 \%)$ \\
\hline First course-therapy & Limb amputation & $625(1 \%)$ \\
& Lymphadenectomy & $388(0.6 \%)$ \\
Chemotherapy & $9429(14 \%)$ \\
& Radiotherapy & $5481(8.2 \%)$ \\
Retroperitoneal resection & $3668(5.5 \%)$ \\
Wide tumoral excision & $26984(40.3 \%)$ \\
Simple tumoral resection & $20277(30.4 \%)$ \\
\hline Death & $17212(25.7 \%)$ \\
\hline & Censoring & $49640(74.3 \%)$ \\
\hline
\end{tabular}

Even though histopathological and molecular data are not available in the databases, it was possible to identify and correlate anatomical location (identified according to the ICD-10) and the choice of initial treatment. From a total of 625 patients who underwent limb amputation, 420 of them (67.2\%) had their STSs located in the lower limbs or hips (ICD 10 C49.2), and 157 patients (25.12\%) with upper limbs or shoulders compromised by STS (ICD 1049.1 ). From the 20,277 patients who underwent local wide excision of their STS, 8,734 of them had their tumor located at their head or neck (ICD C49.0), followed by invasive STS without a defined location and unspecified location (C49.9 and C49.8 respectively).

For survival analysis, a sub-cohort was stablished including only patients with follow-up longer than 10 years, with a registered diagnosis between years 2000 and 2011. In this sub-cohort 39,426 patients were 
evaluated and 13,501events (deaths) were observed. The median overall survival was 84 months ( $82-87$ 95\% Cl), approximately 7 years, as shown on Figure 1.

The 1-, 5- and 10-year survival rate of the patients was, respectively, $81,7 \%(95 \% \mathrm{Cl}=81.3 \%-82,1 \%), 57.2 \%$ $(95 \% \mathrm{Cl}=56.6 \%-57.8 \%)$ and $41.8 \%(95 \% \mathrm{Cl}=41 \%-42.7 \%)$. Survival rate was lower amongst men, with 1-, 5and 10 -year survival rate of, respectively $79 \%(95 \% \mathrm{Cl}=78.3 \%-79.6 \%), 51.1 \%(95 \% \mathrm{Cl}=50.2 \%-52 \%)$ and $34.6 \%(95 \% \mathrm{Cl}=33.4 \%-35.9 \%)$, as well as in elderly patients (>65years of age) with $1-, 5$ - and 10 -year survival rate of, respectively, $79.28 \%(95 \% \mathrm{Cl}=78.48 \%-80.1 \%), 45.63 \%(95 \% \mathrm{Cl}=44.5 \% \%-46.8 \%)$ and $22.1 \%$ $(95 \% \mathrm{Cl}=20.7 \%-23.7 \%)$ (Figure 2).

Surgery was the first treatment modality in $77.7 \%$ of the cases from the original cohort of 66,852 STS patients, and, focusing on first type of surgical procedure, $70.7 \%$ of the patients underwent specific upfront tumoral excision, with $40.3 \%$ of the cohort undergoing wide tumoral excisions as first registered treatment, and $30.4 \%$ of the cohort undergoing simple tumoral excisions.

Regarding the the combination of surgery, systemic chemotherapy and radiotherapy, as treatment options, the regimen for the STS treatments was diverse(all therapeutic modalities - combined or not - were specified at Table 2). Aproximately $20.7 \%$ of the patients were only submitted to clinical treatment with: chemotherapy exclusively $(11,38 \%)$, radiotherapy exclusively $(6,3 \%)$ or to a combination of both $(3 \%)$, without undergoing surgery, during the entire length of the cohort (Table 2). From the $51,942(77,7 \%$ of the original cohort) patients who started their treament by undergoing a surgical procedure, for $48,877(73.1 \%$ of the original cohort) surgery was the only therapy performed.

Table 2: Complete Therapeutic Approach of the STS Patient Throughout the Cohort 


\begin{tabular}{|ll|}
\hline & Soft-tissue Sarcoma Patients \\
\hline Total & $66852(100 \%)$ \\
\hline Surgery only & $48877(73.1 \%)$ \\
\hline Chemotherapy only & $7611(11.38 \%)$ \\
\hline Radiotherapy only & $4246(6.3 \%)$ \\
\hline Chemotherapy + Radiotherapy & $1977(3 \%)$ \\
\hline Adjuvant Rt & $1261(2 \%)$ \\
\hline Adjuvant Qt & $1154(1.7 \%)$ \\
\hline Adjuvant Qt+Rt & $646(1 \%)$ \\
\hline Neoadjuvant Qt & $372(0.5 \%)$ \\
\hline Neoadjuvant Rt & $279(0.4 \%)$ \\
\hline Neoadjuvant Qt and Adjuvant Qt +Rt & $119(0.2 \%)$ \\
\hline Neoadjuvant Qt and Adjuvant Rt & $82(0.12 \%)$ \\
\hline Neoadjuvant Rt and Adjuvant Qt & $68(0.10 \%)$ \\
\hline Neoadjuvant Qt+Rt & $42(0.06 \%)$ \\
\hline Neoadjuvant Qt +Rt and Adjuvant Qt & $46(0.06 \%)$ \\
\hline Neoadjuvant Rt and Adjuvant Qt + Rt & $26(0.03 \%)$ \\
\hline Neoadjuvant and Adjuvant Qt & $17(0.02 \%)$ \\
\hline Neoadjuvant and Adjuvant Rt & $10(0.01 \%)$ \\
\hline Neoadjuvant and Adjuvant Qt + Rt & $10(0.01 \%)$ \\
\hline Neoadjuvant Qt +Rt and Adjuvant Rt & $9(0.01 \%)$ \\
\hline
\end{tabular}

Qt: Chemotherapy; Rt: Radiotherapy

The following characteristics were associated to lower survival rates in univariate analysis: male gender $(\mathrm{HR}=1.445 ; 95 \% \mathrm{Cl}=1.402-1.489) ;$ Midwest $(\mathrm{HR}=1.249 ; 95 \% \mathrm{Cl}=1.177-1.326)$, Southeast $(\mathrm{HR}=1.168 ; 95 \%$ $\mathrm{Cl}=1.133-1.204)$ and South $(\mathrm{HR}=1.18 ; 95 \% \mathrm{Cl}=1.138-1.225)$ regions; age above 65 years old $(\mathrm{HR}=1.61$; $95 \% \mathrm{Cl}=1.56-1.66)$;cancer diagnosis between 2004 and 2007(HR= 1.229; $95 \% \mathrm{Cl}=1.181-1.279)$; tumor located at the abdomen and pelvis $(\mathrm{HR}=1.271 ; 95 \% \mathrm{Cl}=1.193-1.354)$, peritoneum and retroperitoneum ( $\mathrm{HR}=$ $1.568 ; 95 \% \mathrm{Cl}=1.505-1.633)$ and thorax and torso $(\mathrm{HR}=1.206 ; 95 \% \mathrm{Cl}=1.137-1.278)$; clinical stage 3 ( $\mathrm{HR}=$ $1.526 ; 95 \% \mathrm{Cl}=1.448-1.607)$ or $4(\mathrm{HR}=2.743 ; 95 \% \mathrm{Cl}=2.644-2.846)$ at the moment of first treatment, patientsfirst treated with chemotherapy $(\mathrm{HR}=2.546 ; 95 \% \mathrm{Cl}=2.463-2.633)$, radiotherapy $(\mathrm{HR}=1.47 ; 95 \% \mathrm{Cl}$ 
=1.407-1.537), who underwent limb amputation( $\mathrm{HR}=1.923 ; 95 \% \mathrm{Cl}=1.711-2.162)$ or retroperitoneal resections $(\mathrm{HR}=1.367 ; 95 \% \mathrm{Cl}=1.296-1.443)$ as first surgical approach (Table 3).

Table 3: Univariate analysis: patient and tumor characteristics impact on survival 


\begin{tabular}{|c|c|c|c|}
\hline & & HR (95\% IC) & $p$ value \\
\hline \multicolumn{4}{|l|}{ Total } \\
\hline Sex & Male & $1.445(1.402-1.489)$ & $\begin{array}{l}p=<2 e- \\
16\end{array}$ \\
\hline \multirow[t]{7}{*}{ Race } & Asian & $\begin{array}{l}0.6606(0.5481- \\
0.7962)\end{array}$ & $p=1 e-05$ \\
\hline & White & \multirow{2}{*}{1.055 (1.018-1.093) } & $p=0.003$ \\
\hline & Indigenous & & $p=0.6$ \\
\hline & Non-Caucasian (Mixed) & \multirow{2}{*}{$\begin{array}{l}1.333(0.5003-3.553) \\
0.8714(0.8325- \\
0.912)\end{array}$} & $p=3 e-09$ \\
\hline & Black & & $p=0.7$ \\
\hline & \multirow[t]{2}{*}{ Undetermined } & $\begin{array}{l}0.9761 \text { (0.8678- } \\
1.098)\end{array}$ & $p=0.008$ \\
\hline & & $1.042(1.011-1.075)$ & \\
\hline \multirow[t]{6}{*}{ Region } & Midwest & $1.249(1.177-1.326)$ & $p=2 e-13$ \\
\hline & Northeast & $\begin{array}{l}0.7253(0.7017- \\
0.7497)\end{array}$ & $\begin{array}{l}p=<2 e- \\
16\end{array}$ \\
\hline & & 0.8187 (0.7478- & $\mathrm{p}=<2 \mathrm{e}-$ \\
\hline & Southeast & $0.8962)$ & 16 \\
\hline & \multirow[t]{2}{*}{ South } & $1.168(1.133-1.204)$ & \multirow{2}{*}{$\begin{array}{l}p=<2 e- \\
16 \\
p=<2 e- \\
16\end{array}$} \\
\hline & & 1.18 (1.138-1.225) & \\
\hline \multirow[t]{8}{*}{ Age at diagnosis } & $18--25$ & \multirow{2}{*}{$\begin{array}{l}0.8466(0.7931- \\
0.9038)\end{array}$} & \multirow{3}{*}{$\begin{array}{l}p=6 e-07 \\
p=<2 e- \\
16\end{array}$} \\
\hline & $26-35$ & & \\
\hline & $36-45$ & $\begin{array}{l}0.6517(0.614- \\
0.6916)\end{array}$ & \\
\hline & $46-55$ & $\begin{array}{l}0.6873(0.654- \\
0.7223)\end{array}$ & $\begin{array}{l}p=<2 e- \\
16\end{array}$ \\
\hline & $56--65$ & \multirow{2}{*}{$\begin{array}{l}0.8302 \text { (0.7973- } \\
0.8643)\end{array}$} & \\
\hline & \multirow[t]{3}{*}{$>65$} & & \\
\hline & & $1.005(0.9685-1.043)$ & \\
\hline & & $1.61(1.561-1.66)$ & 16 \\
\hline \multirow[t]{4}{*}{ Year of diagnosis } & $2000-2003$ & \multirow{2}{*}{$\begin{array}{l}0.9889(0.9512- \\
1.028)\end{array}$} & $p=0.6$ \\
\hline & $2004-2007$ & & $\mathrm{p}=<2 \mathrm{e}-$ \\
\hline & $2008-2011$ & \multirow{2}{*}{$\begin{array}{l}1.229(1.181-1.279) \\
0.9368(0.9078- \\
0.9668)\end{array}$} & \multirow{2}{*}{$\begin{array}{l}\mathrm{p}=<5 \mathrm{e}- \\
05\end{array}$} \\
\hline & $2012-2015$ & & \\
\hline
\end{tabular}




\begin{tabular}{|c|c|c|c|}
\hline & & $\begin{array}{l}0.933(0.8979- \\
0.9695)\end{array}$ & $p=4 e-04$ \\
\hline \multirow{9}{*}{$\begin{array}{l}\text { Anatomic location of the } \\
\text { sarcoma }\end{array}$} & Abdomen and pelvis & $1.271(1.193-1.354)$ & $p=9 e-14$ \\
\hline & \multirow{2}{*}{$\begin{array}{l}\text { Head and neck } \\
\text { Lower limbs }\end{array}$} & \multirow{2}{*}{$\begin{array}{l}0.9076(0.8725- \\
0.9442)\end{array}$} & \multirow{2}{*}{$\begin{array}{l}p=1 e-16 \\
p=0.8\end{array}$} \\
\hline & & & \\
\hline & Upper limbs & $1.005(0.9629-1.049)$ & \multirow{2}{*}{$\begin{array}{l}p=<2 e- \\
16\end{array}$} \\
\hline & Peritoneum and & $\begin{array}{l}0.7841(0.7475- \\
0.8225)\end{array}$ & \\
\hline & \multirow{2}{*}{ Thorax and torso } & $1.568(1.505-1.633)$ & $\begin{array}{l}p=<2 e^{-} \\
16\end{array}$ \\
\hline & & $1.206(1.137-1.278)$ & \multirow{2}{*}{$\begin{array}{l}p=<2 e- \\
16\end{array}$} \\
\hline & $\begin{array}{l}\text { Invasive without specific } \\
\text { location }\end{array}$ & $\begin{array}{l}0.7306(0.6947- \\
0.7683)\end{array}$ & \\
\hline & Undetermined & $\begin{array}{l}0.9772(0.9405- \\
1.015)\end{array}$ & $\begin{array}{l}p=<2 e- \\
16\end{array}$ \\
\hline \multirow[t]{5}{*}{ Tumor grade at diagnosis } & G1 & $1.492(1.411-1.577)$ & \multirow{2}{*}{$\begin{array}{l}p=<2 e- \\
16\end{array}$} \\
\hline & G2 & 1.768 (1.569-1.991) & \\
\hline & G3 & $1.623(1.501-1.755)$ & 16 \\
\hline & $\mathrm{GX}$ & $\begin{array}{l}0.6221(0.5952- \\
0.6502)\end{array}$ & $\begin{array}{l}p=<2 e- \\
16\end{array}$ \\
\hline & & & $\begin{array}{l}p=<2 e- \\
16\end{array}$ \\
\hline \multirow[t]{5}{*}{ Clinical stage at diagnosis } & Stage 1 & $\begin{array}{l}0.9508(0.8501- \\
1.063)\end{array}$ & \multirow{3}{*}{$\begin{array}{l}p=0.4 \\
p=0.1 \\
p=<2 e- \\
16\end{array}$} \\
\hline & Stage 2 & $0.9507(0.89-1.016)$ & \\
\hline & & & \\
\hline & \multirow{2}{*}{ Undetermined } & $2.743(2.644-2.846)$ & $\begin{array}{l}\mathrm{p}=<2 \mathrm{e}- \\
16\end{array}$ \\
\hline & & $\begin{array}{l}0.4894(0.4745- \\
0.5048)\end{array}$ & $\begin{array}{l}p=<2 e- \\
16\end{array}$ \\
\hline \multirow[t]{7}{*}{ First course-therapy } & Limb amputation & $1.923(1.711-2.162)$ & \multirow{2}{*}{$\begin{array}{l}p=<2 e- \\
16\end{array}$} \\
\hline & Lymphadenectomy & $1.142(0.9931-1.314)$ & \\
\hline & Chemotherapy & $2.546(2.463-2.633)$ & $p=0.06$ \\
\hline & Radiotherapy & $1.47(1.407-1.537)$ & $\begin{array}{l}p=<2 e^{-} \\
16\end{array}$ \\
\hline & Retroperitoneal resection & $1.367(1.296-1.443)$ & \multirow{2}{*}{$\begin{array}{l}p=<2 e- \\
16\end{array}$} \\
\hline & Wide tumoral excision & \multirow{2}{*}{$\begin{array}{l}0.6665(0.6449- \\
0.6887)\end{array}$} & \\
\hline & Simple tumoral resection & & $\begin{array}{l}\mathrm{p}=<2 \mathrm{e}- \\
16\end{array}$ \\
\hline
\end{tabular}


Source: $\mathrm{p}$ value determined by Score (logrank) test

From all the 66,852 patients of the original cohort we performed a sensitivity analysis with, 39,426 of them diagnosed between 2000 and 2011 had their survival analyzed. From that sub-cohort, 9,969 that had clinical stage registered, as stage was not a data collected by SUS before 2008. Within this group, 4,568 individuals were stage IV at diagnosis, representing $59.12 \%$ of all patients clinically staged.

When analyzing the 4,568 clinically staged patients, we observed a 1-, 5- and 10-year survival rate reaching $72.5 \%$ (95\% Cl $=71.7 \%-73.4 \%), 39.1 \%(95 \% \mathrm{Cl}=38,1 \%-40.2 \%)$, and $26 \%(95 \% \mathrm{Cl}=24,7 \%-27,3 \%)$, respectively. Different survival rates, mainly within the groups of patients who underwent limb amputation, lymphadenectomy and retroperitoneal resection, were also observed as shown in the Kaplan-Meier curves below, after the exclusion of the non-staged patients from the survival analysis (Figure 3).

Regarding patients' survival rates according to each specific clinical stage in the sensitivity analysis of the ones diagnosed from 2000 to 2011, the following 1-, 5- and 10-year values were observed: stage 1 with $88 \%$ (95\% Cl = 85.5\%-90.7\%), 57.6\% (95\% Cl = 53.4\%-62.2\%), and40.6\% (95\% Cl = 35.2\%-46.9\%), respectively; stage 2 with $84.3 \%$ (95\% $\mathrm{Cl}=82.7 \%-86 \%), 56.5 \%(95 \% \mathrm{Cl}=54 \%-59.1 \%)$, and $41.9 \%(95 \% \mathrm{Cl}=38.7 \%-45.2 \%)$, respectively; stage 3 with $74.3 \%$ (95\% $\mathrm{Cl}=72.5 \%-76.2 \%), 42.5 \%(95 \% \mathrm{Cl}=40.3 \%-44.9 \%)$, and $28.6 \%(95 \% \mathrm{Cl}$ $=25.8 \%-31.6 \%)$, respectively, and stage 4 with $63 \%(95 \% \mathrm{Cl}=61.5 \%-64.5 \%), 26 \%(95 \% \mathrm{Cl}=24.5 \%-27.6 \%)$, and $14.78 \%(95 \% \mathrm{Cl}=13.23 \%-16.5 \%)$, respectively(Figure 4$)$.

\section{Discussion}

Including 66,852 patients, this is the largest study with epidemiological and clinical aspects of STS in Brazil, with data from all states of the five Brazilian regions and covering a long time-frame (16 years). Some international studies have been conducted by compiling health-care generated data in order to better know the STS patient profile and to acknowledge the impact of this disease all over the world, such as Saltus, in $2018^{(3)}$ in Germany, and Burningham, in $2012^{(1)}$ in the United States. Brazil has more than 210 million inhabitants, a highly admixed population and peculiar access to health care, since more than $70 \%$ of the Brazilian population count on its public health services for cancer care. Exploring potentiality of available Brazilian data to explore epidemiology STS profile is fundamental for governmental planning, health technologies and health economics assessment, and it may help other LMICs by mirroring their realities.

Epidemiologically, there was an almost even distribution between genres, with a slight majority of the patients being female (50.7\%), aged above 65 years old (33\%), of white race $(18,1 \%)$ and living in the Northeast region (40,2\%). However, the male gender, aged above 65 years old and with STS of the peritoneum and retroperitoneum, thorax and torso showed worst prognostic predictors. The epidemiological 
profile of the Brazilian STS patient showed to be similar to the ones described by other international cohorts. In Germany, Saltus ${ }^{(3)}$ describes their patients as evenly distributed between males and females, aged above 65 years old and with tumors located most commonly in the lower extremity, trunk and head and neck. In Canada, Bozzo ${ }^{(4)}$ described the STS population with a slight tendency to male (1.5:1 ratio male to female) and aged above 50 years old in $68 \%$ of the cases. Regarding the American population of STS patients, the AJCC described the STS patients as with a tendency to male $(53,7 \%)$, with STS mostly located on lower extremities $(57,5 \%)$ and with a mean age of 59 years old ${ }^{(5)}$.

Regarding the STS localization results, the large number of head and neck STS patients was cautiously analyzed. As mentioned, the anatomical location was identified and determined according to the ICD-10, and it is important to highlight that "Malignant neoplasm of connective and soft tissue of head, face and neck" and "Malignant neoplasm of other connective and soft tissue" have a slight similar coding, (respectively C49.0 and C49), and the original SIM and SIA registry requires a 3 digit ICD-10 code, which may have mistakenly increased the notification under "head and neck" anatomic location by the erroneous addition of an extra 0 during the digitalization of official forms. This analysis is corroborated after the analysis of the correlation of procedures performed according to each specific anatomic location (TABLE IN ATTACHMENTS).

ATTACHMENT 1: Distribution of procedures based on anatomic location

\begin{tabular}{|c|c|c|c|c|c|c|c|c|c|}
\hline $\begin{array}{l}\text { Anatomic Location } \\
\text { Type of Procedure }\end{array}$ & $\begin{array}{l}\text { C49.4 } \\
+ \\
\text { C49.5 }\end{array}$ & C49.0 & C49.8 & C49.9 & C49.2 & C49.1 & $\begin{array}{l}\text { Any } \\
\text { C48 }\end{array}$ & $\begin{array}{l}\text { C49.3 } \\
+ \\
\text { C49.6 }\end{array}$ & TOTAL \\
\hline Limb amputation & 4 & 4 & 4 & 17 & 420 & 157 & 16 & 3 & 625 \\
\hline Lymphadenectomy & 10 & 55 & 19 & 140 & 10 & 10 & 117 & 27 & 388 \\
\hline Chemotherapy & 742 & 1132 & 324 & 1931 & 1706 & 1410 & 1342 & 842 & 9429 \\
\hline Radiotherapy & 505 & 1147 & 183 & 1157 & 1225 & 506 & 278 & 480 & 5481 \\
\hline $\begin{array}{l}\text { Retroperitoneal } \\
\text { resection }\end{array}$ & 2 & 2 & 3 & 5 & & & 3656 & & 3668 \\
\hline $\begin{array}{l}\text { Wide tumoral } \\
\text { excision }\end{array}$ & 1240 & 8734 & 4094 & 6651 & 1792 & 1587 & 1185 & 1701 & 26984 \\
\hline $\begin{array}{l}\text { Simple tumoral } \\
\text { resection }\end{array}$ & 764 & 4852 & 4546 & 804 & 3288 & 4772 & 74 & 1177 & 20277 \\
\hline TOTAL & 3267 & 15926 & 9173 & 10705 & 8441 & 8442 & 6668 & 4230 & 66852 \\
\hline
\end{tabular}

When first course treatment was analyzed, patients who underwent specific resection of their tumors had a better prognosis (Wide tumoral excision, $\mathrm{HR}=0.6665 ; 95 \% \mathrm{Cl}=0.6449-0.6887$ and Simple tumoral resection with an $\mathrm{HR}=0.499 ; 95 \% \mathrm{Cl}=0.4799-0.5188$ ) and, according to the Kaplan-Meier survival analysis (Figure 3), had a significant better survival rate than the other treatment modalities, with initial lymphadenectomy and limb amputation being the least performed procedures. These results go in accordance with the standard 
treatment of the STS, where an adequate (and wide if necessary) resection is indicated, with a predilection

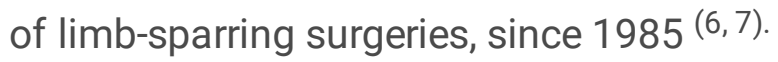

Regarding the use of chemotherapy and radiotherapy on the sarcoma patient, literature indicates the use of radiotherapy, currently, in neoadjuvant or in adjuvant settings in order de improve local control rate and decrease the recurrence rate (mainly in extremity STS), but has no improvement in overall survival. The ESMO recommendation favors adjuvant radiotherapy when tumors size is above $5 \mathrm{~cm}$ or deeply located or high grade and when not RO resection occurs and NCCN recommends neoadjuvant radiation therapy with external beam for microscopic residual disease control and adjuvant treatment when insufficient margins, with local control rates of $95 \%$ with preoperative RT and negative margins, but reinforces that radiotherapy is not substitute for the definitive surgical resection $(8,9)$. The use of chemotherapy, both neoadjuvant or adjuvant, remains controversial with benefits described as the facilitation of surgery, when used perioperatively, or in a systemic modality, with anthracyclines with ifosfamides for high risk patients with thoracic or extremity STS ${ }^{(8)}$.

Treatment wise, the Brazilian are, apparently, in resonance with European and American practices. When we correlate the data on clinical staging, type of first course procedure and combination of clinical and surgical approaches, we observed that the vast majority of patients who underwent only chemotherapy were, in its majority, clinically staged as 4 . Neoadjuvant radiotherapy or neoadjuvant with adjuvant radiotherapy were mostly administered in patients staged 2 or 3 . If we consider that the non-surgical treatment is reserved for patients with no possibility of surgical intervention, our study had 13.834 who underwent chemotherapy and radiotherapy exclusively or combined, with different proportions of clinical staging distributions, and not only to higher stages. It is important to reinforce that many different histological subtypes of STS have different recommendation of systemic treatment. The lack of information regarding the histological grading and clinical staging of a large number of patients (classified as "GX" and "undetermined clinical staging") is presumed to occur because of sub registration. Due to the large number of patients treated with only surgery (without complementation with chemotherapy or radiotherapy) the filing of SIA forms, in which staging and tumor grading related information is mandatory, was - most likely - not performed. After correlation with all the clinical and surgical treatments analyzed, it is believed that due to the majority of them undergoing simple resection or wide resection and not going through clinical treatment afterwards, presumably, the surgical procedure performed is fully controlling the progression of the disease, and the patients are not being referred to adjuvant systemic treatment.

When comparing survival curves with another countries, it was observed a small difference in 1-year overall survival between the Brazilian an American STS patient. A further analysis of the survival by age shows a worst prognosis when long time survival is evaluated amongst men. After the first year of diagnosis, around $84 \%$ of male and $84.5 \%$ of female STS patients in United States are expected to have survived, compared to $79.5 \%$ and $84.9 \%$, respectively, in Brazil, with the latter demonstrating a slight better result within the female population. The 5-year and 10-year survival data, however, show a rapid decrease in survival of patients from both countries. The worst results are seen with the Brazilian male population with, respectively $51 \%$ and $34,5 \% 5$ - and 10 -year survival rates, compared to $64,9 \%$ and $59,2 \% 5$ - and 10 -year survival rates of the 
American male population. And, regardless of a better overall outcome regarding survival risks, the female population still has a decrease of survival rates amongst American (with 66.5\% and 61.1\% 5- and 10-year survival rates, respectively) and Brazilian women (63.4\% and 49\%5- and 10-year survival rates, respectively). The SEERS database collects cancer incidence data from population-based cancer registries covering approximately 34.6 percent of the U.S. population, with an STS incidence valued less than 6 cases for 100,000. However, the annual incidence of the STS in Brazilian population remains unknown, and was not calculated in this study due to this cohort not being a representation of all sarcoma patients registered on the SUS databases (due to exclusion criteria) or the totality the patients treated for STS in Brazil, as a whole.

By comparing STS data from different populations, it was observed that British patient's survival chance is approximately $7 \%$ lower than the Brazilian ones, and $9.2 \%$ lower when compared to American population within the first year of STS follow up (1-year survival rates of $75 \%, 82 \%$ and $84.2 \%$ respectively). And this order of, potentially, improved outcomes is maintained we compare the rates of 5-year survival data available (65.6\% in United States, $55 \%$ in United Kingdom and 57\% in Brazil). However, it is possible to identify a shift in long term survival comparison when we observe the 10-year survival rates, United Kingdom presenting a better survival rate (45\%) than Brazil (42\%) amongst the STS patients. The values for both countries remain, however, significantly lower than American 10-year survival rate, which reaches $60.1 \%$. The progressive decrease in survival of the Brazilian STS patients might also be related to the fact that the majority of the evaluated patients underwent first treatment for their tumor after 65 years of age, with $33 \%$ of this cohort being constituted of elderly patients $(\mathrm{HR}=1.61 ; 95 \% \mathrm{Cl}=1.561-1.66)^{(10-12)}$.

This study is based on the gathering of information obtained from mandatory forms filled out by health care providers and provide the data for administrative databases. As in the many cohorts, several limitations related to the use of a secondary database can be found in this study, such as inconsistency, inadequacy of collected information, confounding factors and missing information. The difficulties to access this data reinforces the necessity of a unified platform. On account of the coverage of this study and its development based on databases generated by the performance of oncologic treatment for STS (surgical, systemic - with chemotherapy - or loco regional - with radiotherapy), information that is present on medical charts and medical files generated by standard follow up consultations were not available and neither these patients could be accurately identified for this investigation, after the elaboration of the cohort. The Brazilian government is currently working on a unified platform.

A major limitation of this study is the lack of direct access to histopathological, molecular, clinical and therapeutic variables or information of the sarcoma subtypes, making the diagnosis confirmed by the registry of the patient under C48, C48.0, C48.1, C48.2, C48.8, C49, C49.0, C49.1, C49.2, C49.3, C49.4, C49.5, C49.6, C49.8. C49.9) according to the tenth revision of the international classification of diseases (ICD-10), topographic localization associated with the therapeutic utilized (and depending on if the patient underwent systemic treatment) the only mean to infer over the possible subtype of the mass/tumor registered, and the significant number of missing data 
Regardless of that, no other study performed by Brazilian researchers was able to provide data resulting in an estimate of the incidence, considering that the SUS databases available only contemplate about $3 / 4$ of the Brazilian population, or provided an evaluation of the survival of the STS patients (of all subtypes) in Brazil.

\section{Conclusion:}

In this retrospective cohort of 66,852 STS patients treated at the Brazilian public health system from 2000 to 2015 , the 1,5 and 10 y survival were: $82 \%, 57 \%$ and $42 \%$, in line with international data. Male gender, age above 65 years old and with STS of the peritoneum and retroperitoneum, thorax and torso, were identified as negative prognostic predictors. Much is yet to be understood about STS sarcoma patient in Brazil and other LMICs, and comprehensive patient data registration and unified platforms are essential.

\section{Declarations}

- Ethical Aspects

This study was approved by the Faculdade de Ciências Médicas de Minas Gerais (FCMMG) internal review board (IRB) in Belo Horizonte, Brazil and registered under de protocol number: CEP 3.928.928/2020 - 2 . The research was conducted in accordance with all relevant Brazilian guidelines and regulations and followed the criteria of the Declaration of Helsinki.

Informed consent was waived by the ethics committee IRB of the Faculdade de Ciências Médicas de Minas Gerais (FCMMG) once the study was based on variables obtained by the confluence of a secondary publicly available SUS database, without any identification of the patients available from the original source and containing no information that can lead to direct identification of the 66,852 patients.

\section{Data availability:}

The datasets generated during and/or analyzed during the current study are available from the corresponding author on reasonable request.

\section{Author Contributions Statement:}

LOF: Conceived and designed the analysis, Collected the data, Performed statistical analysis, Evaluated results, Wrote the paper.

AAGJ:Conceived and designed the analysis, Collected the data, Performed statistical analysis.

FAA:Conceived and designed the analysis, Collected the data, Performed statistical analysis.

AMA:Conceived and designed the analysis, Collected the data, Performed statistical analysis. MLC:Conceived and designed the analysis, Collected the data, Performed statistical analysis AJAW:Evaluated results, Wrote the paper. 
LCST:Performed statistical analysis, Evaluated results, Wrote the paper.

ANR:Conceived and designed the analysis, Collected the data, Performed statistical analysis, Evaluated results, Wrote the paper.

\section{Competing interests}

The authors have no other relevant affiliations or financial involvement with any organization or entity with a financial interest in or financial conflict with the subject matter or materials discussed in the manuscript.

\section{References}

1. Burningham Z, Hashibe M, Spector L, Schiffman J. The Epidemiology of Sarcoma. Clinical Sarcoma Research. 2012;2:16.

2. SAÚDE MD, INCA. Estimativa 2020. Incidência de Câncer no Brasil. 2019.

3. Saltus CW, Calingaert B, Candrilli S, Lorenzo M, D'Yachkova Y, Otto T, et al. Epidemiology of Adult SoftTissue Sarcomas in Germany. Sarcoma. 2018;2018:5671926.

4. Bozzo A, Seow H, Pond G, Ghert M. Changes in Soft-Tissue Sarcoma Treatment Patterns over Time: A Population-Based Study in a Country with Universal and Centralized Healthcare. Sarcoma. 2019;2019:8409406-.

5. Cates JMM. The AJCC 8th Edition Staging System for Soft Tissue Sarcoma of the Extremities or Trunk: A Cohort Study of the SEER Database. J Natl Compr Canc Netw. 2018;16(2):144-52.

6. Bilgeri A, Klein A, Lindner LH, Nachbichler S, Knösel T, Birkenmaier C, et al. The Effect of Resection Margin on Local Recurrence and Survival in High Grade Soft Tissue Sarcoma of the Extremities: How Far Is Far Enough? Cancers (Basel). 2020;12(9):2560.

7. Endo M, Setsu N, Fujiwara T, Ishii T, Nakagawa M, Yahiro K, et al. Diagnosis and Management of Subcutaneous Soft Tissue Sarcoma. Curr Treat Options Oncol. 2019;20(7):54.

8. Bourcier K, Le Cesne A, Tselikas L, Adam J, Mir O, Honore C, et al. Basic Knowledge in Soft Tissue Sarcoma. Cardiovasc Intervent Radiol. 2019;42(9):1255-61.

9. von Mehren M, Randall RL, Benjamin RS, Boles S, Bui MM, Ganjoo KN, et al. Soft Tissue Sarcoma, Version 2.2018, NCCN Clinical Practice Guidelines in Oncology. J Natl Compr Canc Netw. 2018;16(5):53663.

10. Callegaro D, Swallow CJ. ASO Author Reflections: Every Step Counts: Improved Survival of Retroperitoneal Sarcoma Patients During the Past 15 Years. Ann Surg Oncol. 2020. 
11. Society AC. Survival Rates for Soft Tissue Sarcoma 2020 [Available from: https://www.cancer.org/cancer/soft-tissue-sarcoma/detection-diagnosis-staging/survival-rates.html.

12. UK CR. Survival Soft tissue sarcoma Cancer Research UK 2020 [updated Last reviewed: 09 Apr 2018. Available from: https://www.cancerresearchuk.org/about-cancer/soft-tissue-sarcoma/survival\#.

13. de Lemos LLP, Guerra Junior AA, Santos M, Magliano C, Diniz I, Souza K, et al. The Assessment for Disinvestment of Intramuscular Interferon Beta for Relapsing-Remitting Multiple Sclerosis in Brazil. Pharmacoeconomics. 2018;36(2):161-73.

14. Maia Diniz I, Guerra AAJ, Lovato Pires de Lemos L, Souza KM, Godman B, Bennie M, et al. The long-term costs for treating multiple sclerosis in a 16-year retrospective cohort study in Brazil. PLoS One. 2018;13(6):e0199446.

15. Guerra Junior A, Lemos L, Godman B, Bennie M, Osorio-de-Castro C, Alvares J, et al. HEALTH TECHNOLOGY PERFORMANCE ASSESSMENT: REAL-WORLD EVIDENCE FOR PUBLIC HEALTHCARE SUSTAINABILITY. International Journal of Technology Assessment in Health Care. 2017;33:1-9.

16. Gomes RM, Barbosa WB, Godman B, Costa JO, Ribeiro Junior NG, Simao Filho C, et al. Effectiveness of Maintenance Immunosuppression Therapies in a Matched-Pair Analysis Cohort of 16 Years of Renal Transplant in the Brazilian National Health System. Int J Environ Res Public Health. 2020;17(6).

17. Acurcio FA, Guerra Junior AA, da Silva MRR, Pereira RG, Godman B, Bennie M, et al. Comparative persistence of anti-tumor necrosis factor therapy in ankylosing spondylitis patients: a multicenter international study. Curr Med Res Opin. 2020;36(4):677-86.

18. Cancer; AJCo, Surgeons ACo. AJCC Cancer Staging Form Supplement. $8^{\text {th }}$ ed2018.

\section{Figures}


Overall survival of the Soft-tissue sarcoma patient in Brazil from 2000 to 2011

Strata - All

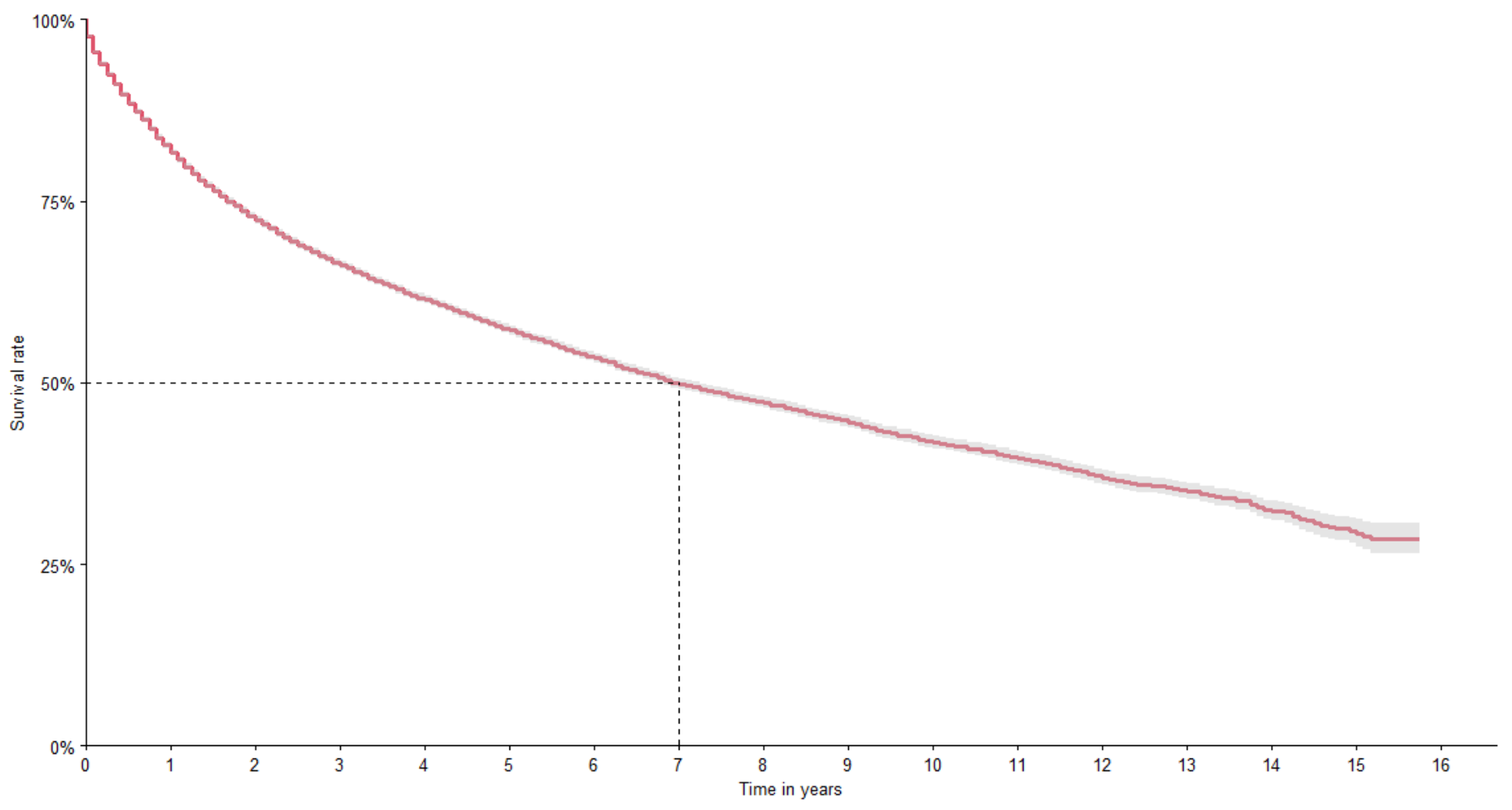

Figure 1

Overall Survival of the Soft-tissue Sarcoma Patient in Brazil from 2000 to 2015 

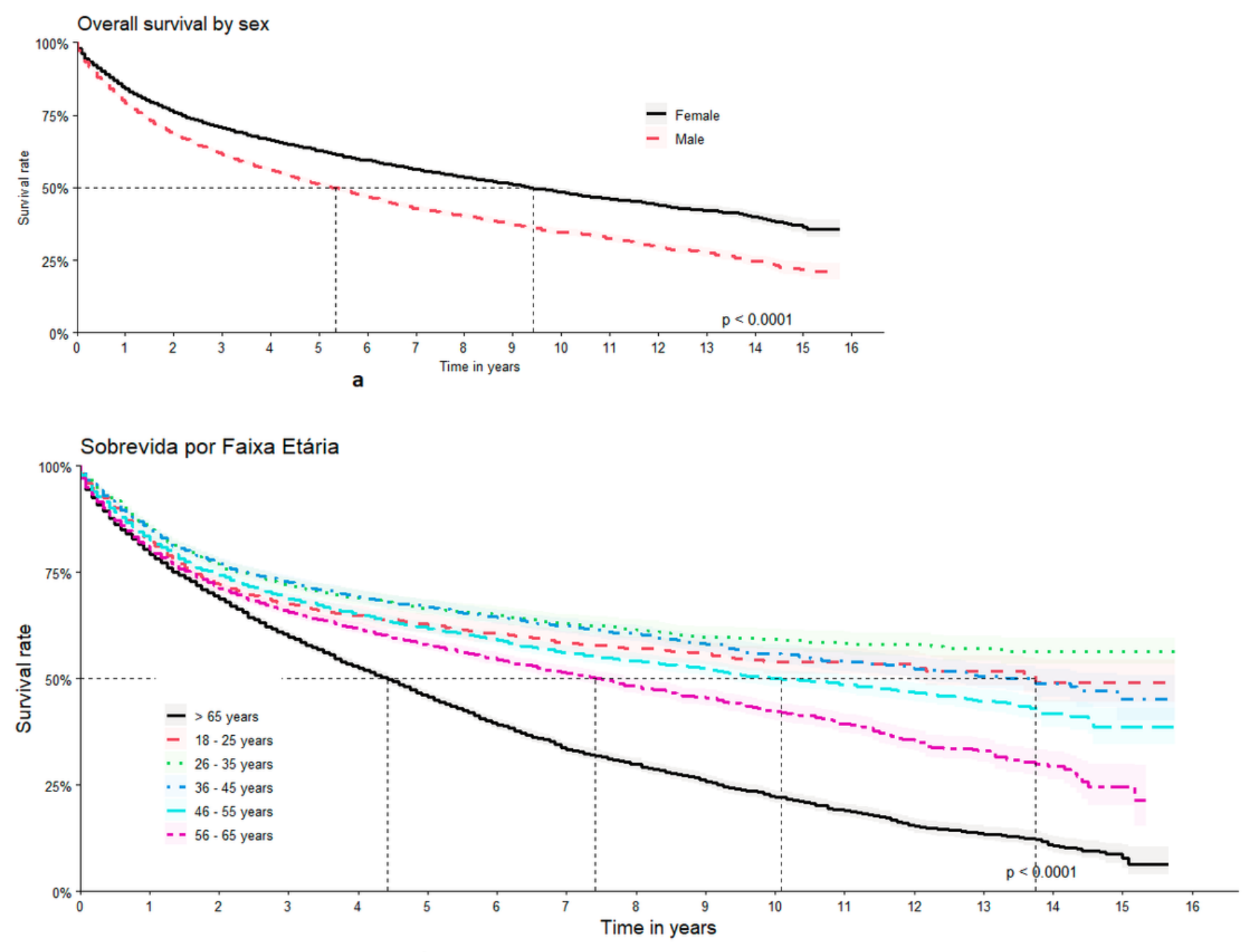

b

Figure 2

Overall Survival by Age and Sex 


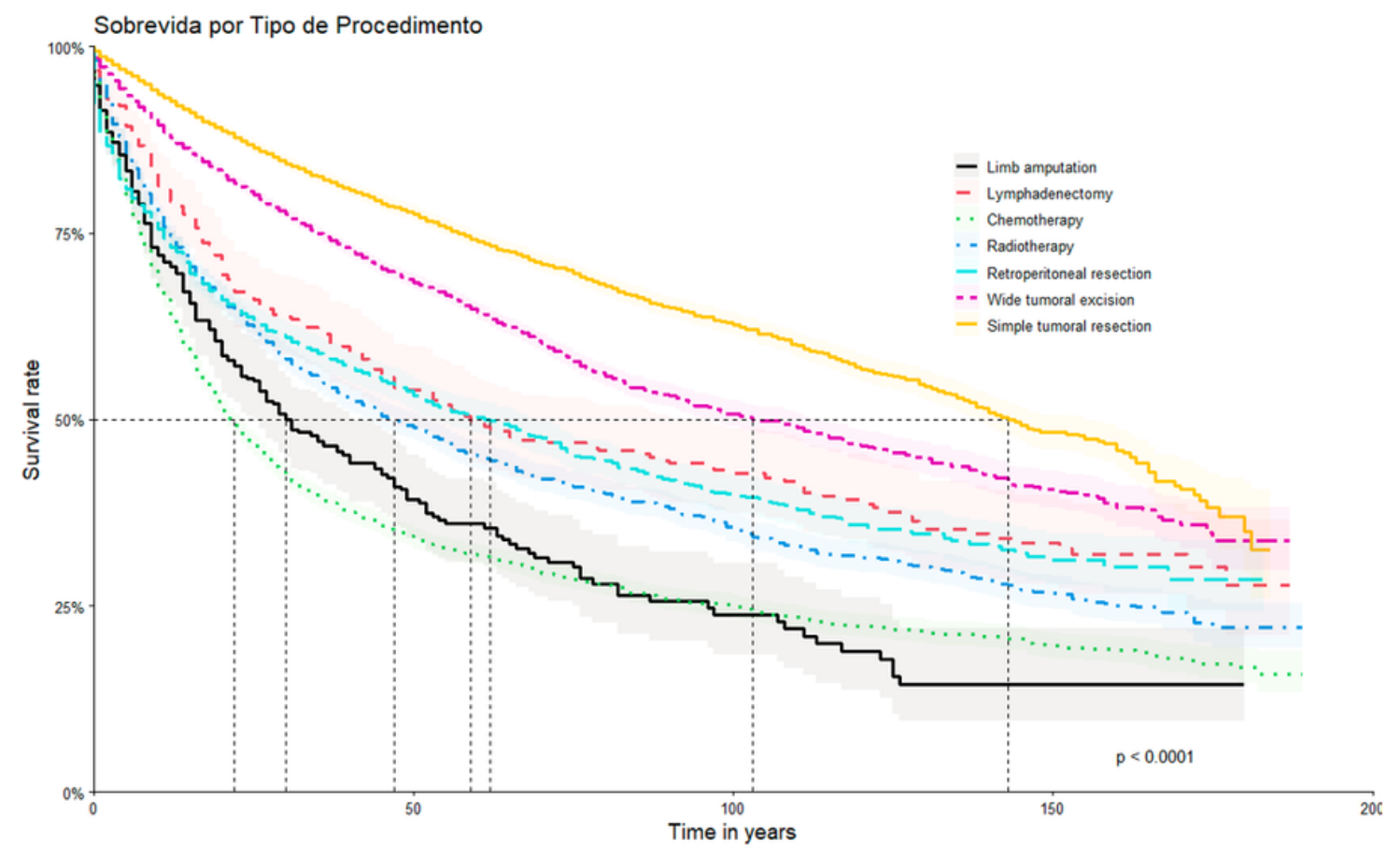

a

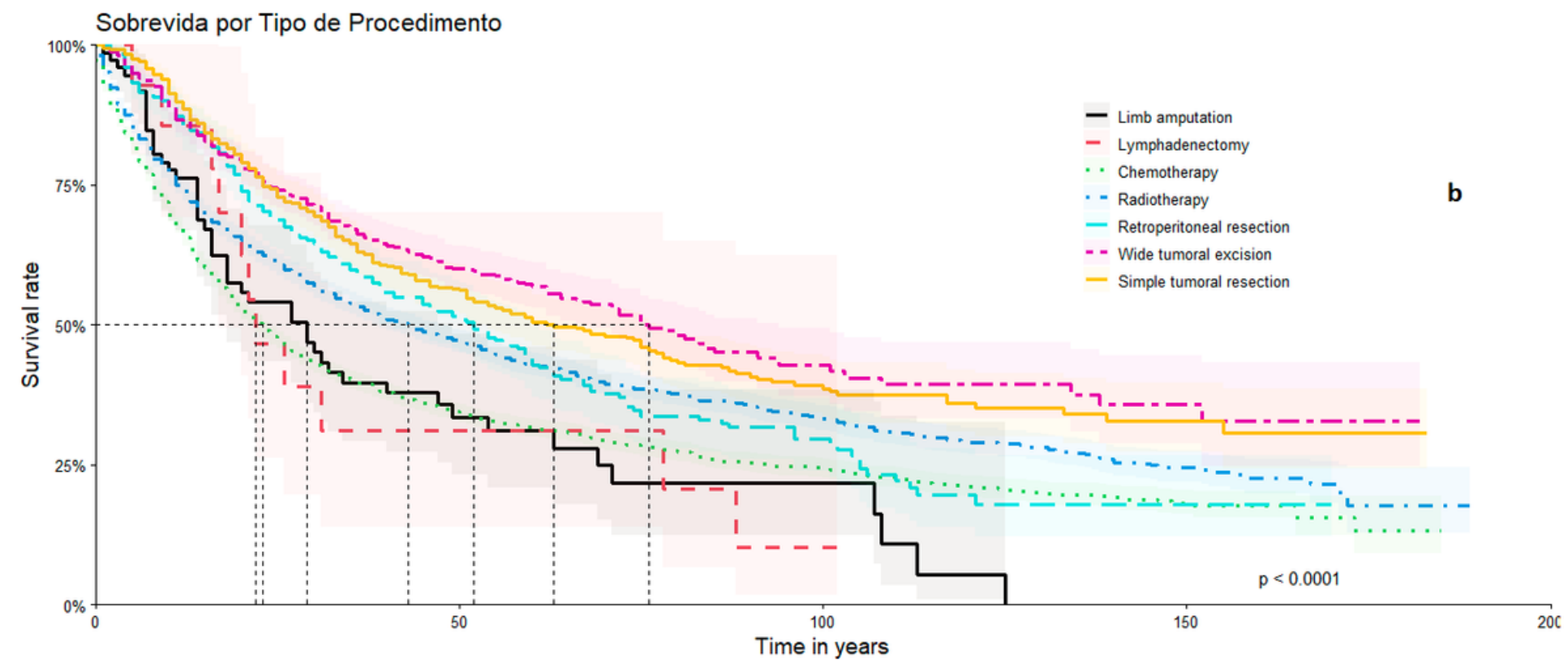

Figure 3

Compared Survival by Type of First Treatment between Full Cohort and Only Staged Patients (Left: Full cohort with 66852 patients. Rlght: Sub-cohort with 13800 staged patients.) 


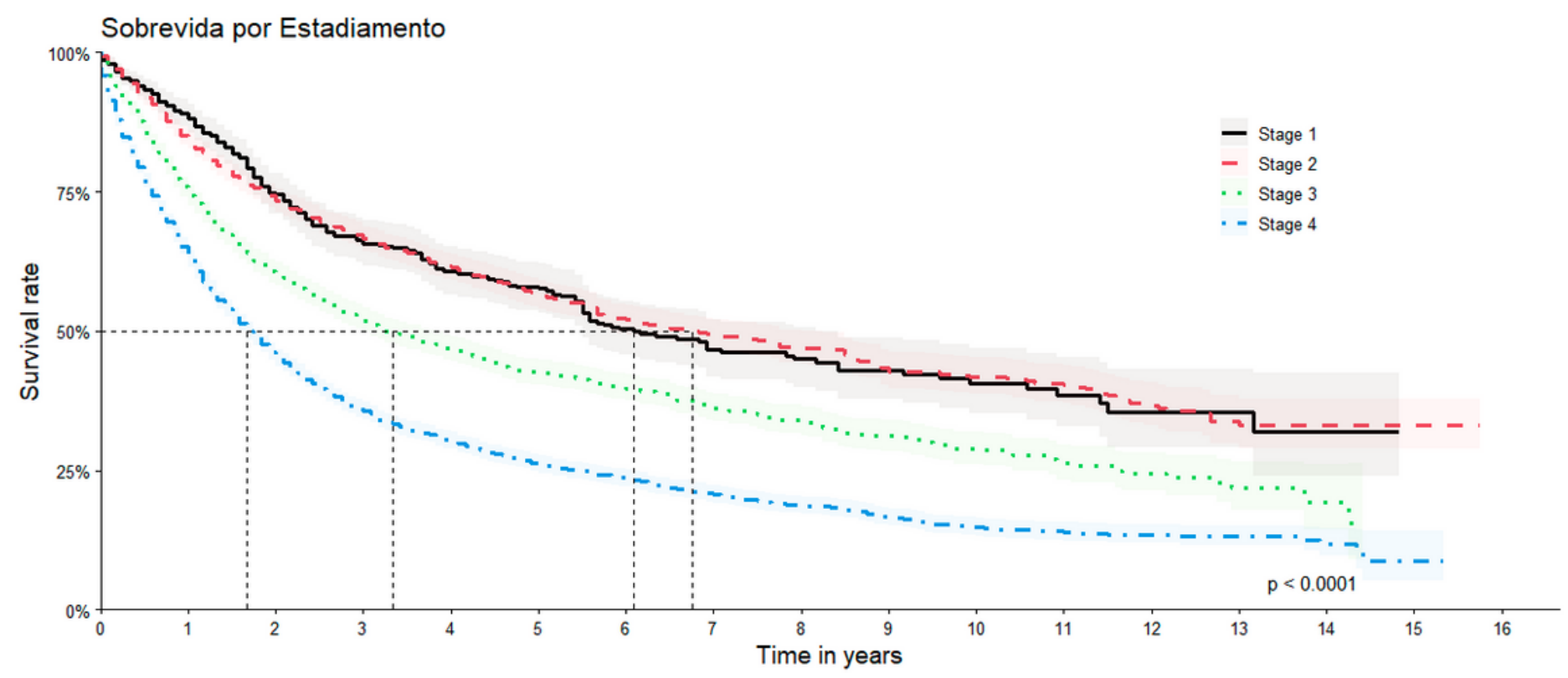

Figure 4

Overall Survival by Clinical Stage
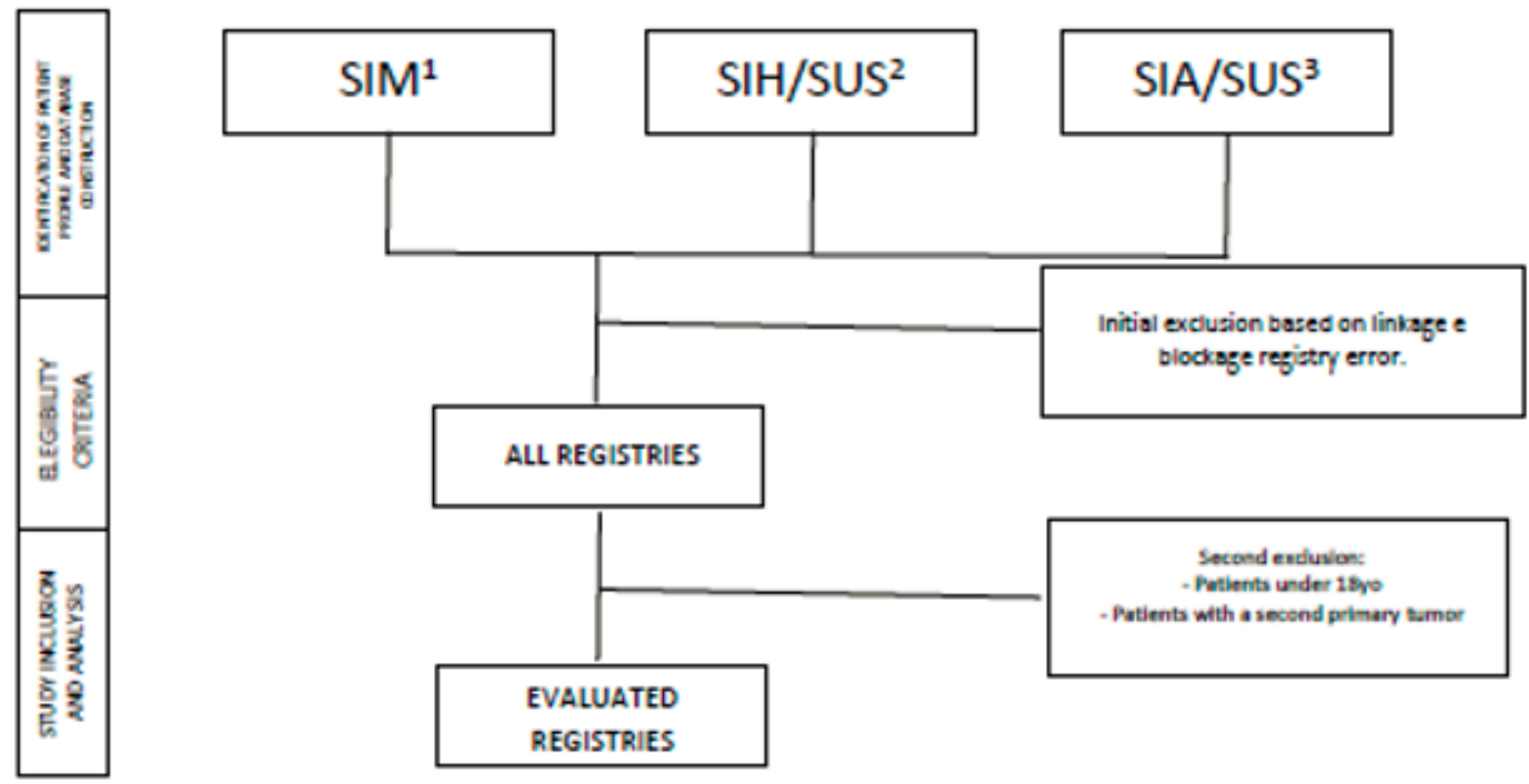

Second enduvion:

- Fatients under 18yo

- Patients with a secend primary tamor

\section{Figure 5}

Study design. 1Mortality Information Systems (SIM), 20utpatient Information System (SIA/SUS), 3Hospital Information System (SIH/SUS). 